\title{
ASPEK SOSIOLINGUISTIK DALAM STIKER HUMOR
}

\author{
Surana \\ FBS UNESA SURABAYA \\ Pos-el: surana@unesa.ac.id
}

\begin{abstract}
Abstrak
Ada dua aspek dalam sosiolinguistik yaitu aspek sosial kemasyarakatan dan aspek linguistik. Mengingat aspek sosiolinguistik dalam stiker humor ini juga terkait dengan wujud stiker itu sendiri yang juga merupakan sebuah wacana pendek, maka uraian tentang analisis wacana juga akan dipaparkan dalam tulisan ini (Roberson, D., 2016). Jadi, dalam tulisan berikut diuraikan berbagai aspek sosial yang hanya menyangkut peserta tutur, kebahasaan, dan wujud stiker yang berupa sebuah wacana, dengan metode sosiolinguistik. Aspek sosiolinguistik terdiri atas dua aspek yakni aspek sosial kemasyarakatan dan aspek kebahasaan. Hymes (1972) merumuskan pendapatnya tentang aspek sosiolinguitik dengan menyebutnya sebagai konteks dengan singkatan SPEAKING. Fishman (1968) dengan sebuah konsep yang disimpulkan dalam pernyataan: "Who speak, What language to whom, when and what end" siapa berbicara dengan bahasa apa, kepada siapa, kapan dan mengenai masalah apa. Pendapat yang lebih luas dikemukakan oleh Poedjosoedarmo. Konteks tuturan diartikan dengan komponen tutur yang meliputi 12 hal yang disingkat dengan memoteknik $\mathrm{O}, \mathrm{O}, \mathrm{E}, \mathrm{M}, \mathrm{A}, \mathrm{U}$, B, I, C, A, R, A. Konteks dengan aspek-aspek situasi tutur berdasar Leech meliputi 5 (lima) hal yang merupakan kriteria di dalam studi variasi bahasa yakni (1) Penutur dan lawan tutur; (2) Konteks tuturan; (3) Maksud tuturan; (4) Tuturan sebagai bentuk tindakan atau aktivitas; dan (5) Tuturan sebagai produk tindak verbal.
\end{abstract}

Kata kunci: aspek sosiolinguistik, stiker, humor

\section{SOSIOLINGUISTIC ASPECT IN HUMOR STICKER}

\begin{abstract}
There are two aspects in sociolinguistic i.e. social aspect and linguistic aspect. Since the sociolinguistic aspect of the sticker of humor is also related to the form of the sticker itself which is also a short discourse, the description of discourse analysis will also be presented in this paper (Roberson, D., 2016). The following article described various social aspects that only concern with the speech participants, linguistic, and the form of stickers in the form of a discourse are analyzed by sociolinguistic methods. The sociolinguistic aspect consists of two aspects, namely social aspect and linguistic aspect. Hymes (1972) formulated his opinion on the sociolinguistic aspect and named it as a context with the abbreviation SPEAKING. Fishman (1968) with a concept summarized in the statement: "Who speak, What language to whom, when and what end". Other depth opinion is expressed by Poedjosoedarmo. The context of speech is defined by the speech component which includes 12 things that are abbreviated by the mnemotechniques $O, O, E, M, A, U, B, I, C, A, R, A$. The other context according to Leech's speech situation includes 5 matters which are the criteria in the study of variation of language namely (1) speakers and listeners; (2) speech context; (3) the purpose of the speech; (4) speech act; and (5) speech as speech act product.
\end{abstract}

Keywords: sociolinguistic aspects, stickers, humor 


\section{PENDAHULUAN}

Setiap wacana pasti memiliki unsur. Baik unsur internal maupun unsur eksternal. Salah satu unsur eksternal wacana berupa konteks pertuturan. Pada tahun 1972 Hymes telah mengemukakan pelbagai konteks yang dapat mempengaruhi makna dalam suatu interaksi dan komunikasi. Hymes merumuskan konteks tersebut dengan singkatan SPEAKING, yaitu: (1) setting dan scene (S) menyangkut waktu, tempat, dan suasana pembicaraan, (2) participants (P) mengacu pada peserta tutur atau pihak-pihak yang terlibat dalam pembicaraan, (3) Ends (E) berkaitan dengan maksud dan tujuan yang ingin dicapai dalam pembicaraan, (4) Act sequence (A) berkenaan dengan bentuk dan isi tuturan, (5) Key (K) menyangkut nada suara, cara, dan emosi, seperti: santai, serius, senang, sedih, dan sebagainya, (6) Instrumentalities (I) menunjuk pada saluran dan bentuk bahasa yang digunakan, saluran menyangkut: lisan, tulis, telepon, semapore, dan sebagainya, sedangkan bentuk bahasa menyangkut: ragam, dialek, variasi, register, dan sebagainya, (7) Norms of Interaction dan Norms of Interpretation (N) yaitu menyangkut norma-norma atau kaidah-kaidah dalam berbahasa, dan penafsiran terhadap tuturan dari lawan bicara, dan (8) Genre (G) menyangkut tipe tuturan yang dipergunakan untuk berkomunikasi (Andersen, E., 2014).

Dalam peristiwa tutur terjadi interaksi verbal yang selalu melibatkan faktor-faktor yang ada di luar bahasa, antara lain: penutur, lawan tutur, pokok pembicaraan serta waktu tempat bicara. Oleh Fishman (1968) faktor-faktor tersebut disimpulkan dalam pernyataan: "Who speak, What language to whom, when and what end" siapa berbicara dengan bahasa apa, kepada siapa, kapan dan mengenai masalah apa.

Pendapat yang hampir sama dikemukakan oleh Poedjosoedarmo. Konteks tuturan diartikan dengan komponen tutur yang meliputi 13 hal yaitu: (1) Pribadi si penutur atau orang pertama (01); (2) Anggapan penutur terhadap kedudukan sosial dan relasinya dengan orang yang diajak bicara (02); (3) Kehadiran orang ketiga (03); (4) Maksud atau kehendak si penutur; (5) Warna emosi si penutur; (6) Nada suasana bicara; (7) Pokok pembicaraan; (8) Urutan bicara; (9) Bentuk wacana; (10) Sarana tutur; (11) Adegan tutur; (12) Lingkungan tutur; dan (13) Norma kebahasaan lainnya.

Yang dimaksud dengan penutur dan lawan tutur di sini meliputi pula pembicara dan pendengar serta penulis dan pembaca. Di dalam kaitannya dengan penelitian disertasi ini konsep penutur dan lawan tutur memiliki dua dimensi. Bila dianalisis dihubungkan dengan pencipta stiker dan pembacanya, maka dikotomi yang disangkutkan adalah penulis dan pembaca. Akan tetapi, bila dikaitkan dengan stiker, istilah penutur dan lawan tutur yang disangkutkan. Kesemua ini dilakukan mengingat stiker adalah wacana tertulis, dan dialog tokoh-tokohnya tidak dapat dilepaskan hubungannya dengan aspek percakapan yang menampilkan peserta percakapan yang berperan sebagai penutur dan lawan tutur baik secara bergantian maupun tidak.

Tutur, konteks, tujuan, tindak ucap, dan tuturan sebagai produk tindak ucap secara bersama-sama membentuk situasi tutur (speech situation) Leech. Bila diamati secara saksama, kelima kriteria yang digariskan Leech di atas mengisyaratkan bahwa bentuk tuturan yang diutarakan oleh seorang penutur kepada lawan tuturnya selalu dilandasi oleh maksud tertentu. Dalam tindak tutur setiap pihak memiliki alasan-alasan yang jelas didalam mengartikulasikan bentuk-bentuk tuturannya. Mengapa bentuk tuturan tertentu dipilih oleh seseorang bukan bentuk tuturan yang lain. Jadi, tidak ada unsur penutur secara bebas atau semena-mena memproduksi tuturannya. Setiap peserta percakapan 
bertanggungjawab terhadap tindakan dan bahasa yang digunakan, serta segala penyimpangan yang dilakukan di dalam percakapan. Kesemua hal ini sesuai dengan pendapat yang dikemukakan Allan (1986, hlm. 10) berikut ini:

Speaker and hearer mutually recognize that certain conventions govern their actions and their use of language, and also their interpretations of their actions and utturances of the person they are speaking with (i.e their interlocutor). Each interlocutor is held responsible for his actions and language use, and hence his abservation of (or violation of) the convention of language interchange.

\section{METODE}

Guna pemecahan masalah dalam penelitian dapat ditempuh dengan menggunakan berbagai metode yang menurut tahapan strateginya bermula dengan metode dasar yang meliputi 3 (tiga) hal, yakni (1) penyediaan data, (2) analisis data, dan (3) penyajian hasil analisis data.

Pada tahap penyediaan data, peneliti mengumpulkan pelbagai stiker yang didapati di dalamnya beraneka kata, kelompok kata, kalimat, wacana, dan segala ungkapan yang mempunyai ciri slang dan variasi bahasa yang lain. Data dalam penelitian ini diperoleh dari satu sumber saja, yakni sumber tertulis berupa stiker.

Hasil pemerolehan data dari sumber tertulis itu kemudian diklasifikasikan. Alasan yang mendasari pemilihan data dalam bentuk wacana stiker humor adalah kemudahan untuk memperolehnya, yang hampir dapat ditemui di semua tempat dan semua lapisan masyarakat.

Sesudah data tersedia secara cukup, tahap selanjutnya peneliti menganalisis data sesuai dengan masalah dan tujuan penelitian. Analisis data berikut terdapat dua jenis. Pertama, analisis data yang dihubungkan dengan ciri struktur kebahasaan. Kedua, analisis data yang dilakukan dengan mempertimbangkan konteks pemakaiannya. Analisis data ini meliputi tekstual dan kontekstual.

Metode penyajian hasil analisis data ini dibedakan menjadi 2 (dua) yakni metode penyajian hasil analisis dengan perumusan melalui kata-kata biasa, walaupun dengan terminologi yang teknis sifatnya; dan metode penyajian yang merupakan penyajian dengan perumusan memakai tanda dan lambang-lambang. Tahap terakhir dari penelitian ini, yakni tahap penyajian hasil analisis data, akan dilakukan dengan menggunakan metode penyajian dengan penyajian hasil analisis data dengan menggunakan rumusan kata-kata.

\section{HASIL DAN PEMBAHASAN}

Setiap tuturan, atau wacana yang wajar menurut Raskin (1984, hlm. 103) dihasilkan dari komunikasi yang bonafit (bonafide communication). Proses komunikasi ini ditandai dengan kepatuhan terhadap prinsip kerja sama komunikasi dengan kepatuhan terhadap prinsip kerja sama komunikasi. Artinya setiap peserta tutur harus mematuhi pelbagai prinsip kerja sama agar komunikatif tuturan tersebut. Selain itu, para peserta tutur tentunya harus mematuhi pelbagai prinsip kesopanan agar tercipta suatu komunikasi yang saling menghargai di antara peserta tutur. Terakhir, dalam berkomunikasi harus selaras dan sesuai dengan jarak sosial dan status sosial di antara masing-masing peserta tutur dalam parameter pragmatik. Dalam proses komunikasi ini setiap peserta tindak tutur memberikan kontribusi yang logis dan dapat dipertanggungjawabkan. Apabila terjadi penyimpangan, tentunya penyimpangan itu memiliki konsekuensi pragmatis dalam suatu komunikasi.

Apapun istilah yang dipakai pada intinya sebuah tuturan atau sebuah stiker humor terbentuk dengan dipengaruhi oleh pelbagai faktor. Sintesis dari pelbagai 
pendapat di atas mengenai pelbagai faktor yang mempengaruhi tuturan adalah sebagai berikut.

\section{Penutur atau Orang Pertama (01)}

Penutur atau partisipan merupakan peserta tutur dalam suatu interaksi dan komunikasi yang terdiri penyapa atau $\mathrm{O} 1$, pesapa atau $\mathrm{O} 2$, dan pendengar atau $\mathrm{O} 3$ memiliki peranan masing-masing yang sangat penting yang mempengaruhi terbentuknya tuturan. Peranan itu, terkait dengan status sosial mereka, hubungan di antara mereka. Selain itu, jenis kelamin, usia, latar pendidikan, agama atau aliran kepercayaan, prinsip hidup, profesi, dan kondisi kejiwaan sangat mempengaruhi terbentuknya tuturan O1. Di antara partisipan yang ada dalam stiker humor yang merupakan O1 yakni kreator stiker. Konteks ini terkait dengan pribadi pembuat stiker meliputi anggapan dan tujuan membuat stiker. Tujuan O1 membuat stiker di antaranya sebagai curahan hati segala persoalan hidup yang dihadapi dan juga menciptakan hiburan. Anggapan penutur terkait dengan persepsi pembuat stiker terhadap kedudukan sosial dan relasinya terhadap pembaca. Contoh konteks partisipan $\mathrm{O} 1$ dalam stiker humor tampak pada contoh di bawah ini.

(1) Omahku BAnyuwangi

mbahku Dukun santet...

wani nglarani atiku

Kulkas 9 pintu masuk

(2) sorry Ke Perutmu....!!!

GUE

lagi

pengen

SENDIRI

(3) SAYA CUMA

SEGINI ADANYA

KALAU KAMU

SIAP SEDERHANA

PAKAI HELM

NAIK \& DUDUK

DI BELAKANG

KALAU UDAH

KITA CARI

KEBAHAGIAAN

BARENG
(4) Saya phobia

sama

ketinggian,

apalagi sama

orang yg

gayanya

ketinggian.

Pada contoh (1) sampai (4) tampak keberadaan O1. Pada contoh itu O1 muncul dalam bentuk $K u, G U E$, dan saya. Banyak sedikitnya ujaran yang keluar dari mulut seseorang penutur memang ditentukan oleh pribadi penutur itu. Dalam hal ini ada dua hal penting yang perlu disebut: pesapa siapakah 01 itu atau kreator stiker dan kedua dari manakah asal O1 itu. Untuk pertanyaan pertama, ada hal yang penting disebut (1) bagaimanakah keadaan fisik O1, (2) bagaimanakah keadaan mental O1, (3) bagaimana status sosial O1, dan (4) bagaimanakah kemahiran bahasa O1. Seorang penutur yang ompong (tak bergigi) atau memiliki alat ucap yang tidak lengkap, tentu lain bentuk bunyinya jika dibandingkan dengan orang yang memiliki gigi yang lengkap. Demikian pula seorang yang berbibir tebal memiliki kualitas bunyi yang berbeda dengan orang yang berbibir tipis. Seorang penutur yang pemalu, mudah gemetar dan dihinggapi rasa takut, tentu memiliki kebiasaan kebahasaan yang lain dengan orang yang ekstovert, yang pemberani, atau yang periang. Seseorang yang memiliki status sosial tinggi tentu warna bahasa yang digunakan berbeda dengan seseorang yang status sosialnya rendah. Seorang penutur yang fasih dalam penguasaan bahasa yang harus dituturkannya agar mengujarkan bentukbentuk bahasa yang sangat berbeda jika dibandingkan dengan bentuk bahasa yang diujarkan oleh penutur yang mempunyai kemampuan rendah.

Tentang latar belakang asal si penutur kita dapat menyebut hal-hal penting berikut: latar belakang pendidikan, jenis kelamin, asal daerahnya, asal 
golongan kelas masyarakatnya, umurnya, jenis profesinya, kelompok etniknya, dan aliran kepercayaannya. Mungkin masih ada beberapa lagi yang dapat kita sebut, tetapi hal-hal yang paparkan ini termasuk latar belakang yang penting terutama mengenai tujuan membuat stiker, yang paling dominan adalah untuk mencurahkan isi hati.

Keunikan O1 menentukan warna bahasa dan idioleknya. Di samping itu, ia juga menentukan corak dialek yang ia lontarkan, baik dialek geografi, dialek etnik, dialek sosial, dialek jenis kelamin, dialek usia, maupun yang lain-lain. Sangat sulit bagi seseorang untuk meniadakan atau manutup-nutupi kebiasaan orang lain atau kebiasaan dari kelompok masyarakat lain.

\section{Anggapan Penutur terhadap Kedudukan Sosial dan Relasinya dengan Orang Kedua (O2)}

Faktor terpenting kedua yang menentukan bentuk tutur yang keluar dari mulut seseorang penutur ialah orang kedua, yaitu orang yang diajak bicara oleh penutur itu. Orang kedua atau mitra tutur menentukan terbentuknya tuturan yang dihasilkan. Tingkat sosial lawan bicara atau teman bicara ini biasanya menentukan pilihan tinggi rendah tingkat tutur oleh orang kesatu (O1).

Terkait dengan $\mathrm{O} 2$ dalam hal ini yang terpenting ialah anggapan $\mathrm{O} 1$ tentang seberapa tinggi tingkat sosial orang kedua (O2) dan seberapa akrab hubungan antara kedua orang itu. Jikalau O1 menganggap bahwa $\mathrm{O} 2$ orang yang terhormat maka $\mathrm{O} 1$ akan memilih leksikon yang menunjukkan rasa hormat itu untuk $\mathrm{O} 2$ itu. Akan tetapi jika $\mathrm{O} 1$ beranggapan bahwa $\mathrm{O} 2$ orang yang biasa saja, maka O1 tak perlu bersusahsusah mencari bentuk-bentuk linguistik yang menunjukkan rasa hormat. Ia dapat lebih santai. Anggapan O1 terhadap O2 dalam stiker humor ini sama. Ada anggapan status $\mathrm{O} 1$ dan $\mathrm{O} 2$ sama. Oleh karena itu, ragam bahasanya menunjukkan keakraban, ragam santai, dan bahasa yang digunakan tidak baku. Jadi, anggapan $\mathrm{O} 1$ atau pembuat stiker terhadap $\mathrm{O} 2$ atau pembaca memiliki status sosial yang sama, usia yang sama, dan jarak sosial yang sama.

Selanjutnya, seberapa anggapan $\mathrm{O} 1$ terhadap keintiman relasi $\mathrm{O} 1$ dan $\mathrm{O} 2$ juga menentukan corak bahasa yang akan dituturkannya. Jika $\mathrm{O} 1$ menganggap bahwa hubungan antara $\mathrm{O} 1$ dengan $\mathrm{O} 2$ cukup akrab, maka ia akan memilih suatu ragam bahasa yang bernuansa rasa keakraban ini. Pada kebanyakan bahasa suatu bentuk tutur yang di dalamnya terdapat banyak penanggalan (ellipsis) biasanya dianggap dapat memancarkan pengertian akrab ini. Tutur ringkas bias juga memancarkan pengertian intim ini. Pada bahasa Jawa, tingkat tutur ngoko dan madya memancarkan perasaan lebih akrab dari pada tingkat tutur krama. Tentu saja ada hal-hal lain yang khusus terdapat pada bahasa tertentu yang dapat dipakai untuk memancarkan perasaan akrab ini. Di dalam bahasa Inggris dan bahsa yang lain, misalnya, pemanggilan seseorang dengan hanya memakai singkatan nama pertama (first name), dianggap mendatangkan rasa akrab. Dalam bahasa Jawa, ngoko dianggap lebih akrab daripada madya atau krama.

Dalam hal ini yang penting nampaknya bukanlah keadaan objektif tingkat sosial $\mathrm{O} 2$ dan keadaan objektif hubungan pribadi melainkan anggapan yang ada pada O1. Jadi kalau diamati bentuk tutur dan kemudian ingin menghubung-hubungkan dengan keadaan objektif tingkat sosial serta relasi perseorangan yang ada antara O1dengan $\mathrm{O} 2$, maka sering-sering ditemukan suatu kenyataan yang tidak cocok. Artinya, tingkat sosial $\mathrm{O} 2$ mungkin lebih tinggi atau lebih rendah dari kenyataan yang ditunjukkan oleh bentuk-bentuk tutur yang diujarkan, dan relasi pribadi anyara $\mathrm{O} 1$ 
dengan O2 nyatanya tidak seakrab atau sejauh seperti yang tercerminkan pada bentuk tutur.

Apabila hal di atas terjadi, maka kita dapat mengatakan bahwa penilaian $\mathrm{O} 1$ terhadap $\mathrm{O} 2$ agak keliru, dan sebagai akibatnya sebetulnya $\mathrm{O} 2$ tidak begitu suka terhadap perlakuan kebahasaan $\mathrm{O} 1$. O2 telah dipaksa menerima penilaian kebahasaan yang keliru oleh O1. Umumnya bentuk tutur memerlukan adanya O2. Kenyataan tersebut selaras dengan keadaan pada mayoritas stiker yang terbentuk bahwa status $\mathrm{O} 2$ kebanyakan lebih tinggi. Tentunya, $\mathrm{O} 1$ tidak memikirkan hal ini mengingat anggapan dan tujuan membuat stiker yang telah diuraikan di atas. Contoh stiker humor yang dipengaruhi $\mathrm{O} 2$ tampak di bawah ini.

(5) Bahagia itu sederhana,

Sesederhana kamu tersenyum

Dan bersyukur dengan apa yang

Sudah kamu punya.

(6) uripa sapolah-

polahmu

nanging aja nganti

gawe susahing

wong tuwamu

(7) MASIH MENDING GUA JELEK

KARENA CIPTAAN TUHAN!

DARIPADA LU CANTIK CIPTAAN

CAMERA 360 DAN PHOTOSHOP

Pada contoh (5) sampai (7) tampak pengaruh kehadiran O2. Kehadiran O2 ditunjukkan dengan bentuk kamu, uripa, dan $L u$. Tanpa kehadiran bentuk-bentuk itu conto itu tidak jelas $\mathrm{O} 1$ bertutur dengan siapa.

\section{Kehadiran Orang Ketiga (03)}

Kehadiran O3 dalam stiker humor digambarkan sebagai orang yang dibicarakan dan telah memberi inspirasi terciptanya sebuah stiker. Berbeda dengan suatu ujaran dapat berganti bentuknya dari apa yang biasanya terjadi apabila ada seseorang tertentu yang kebetulan hadir pada adegan tutur itu. Dua orang kenalan baik dari suku Jawa terpaksa mengubah bahasa percakapannya dari bahasa Jawa ke bahasa Indonesia, justru karena kebetulan suatu percakapan itu berlangsung ada teman lain dari suku Madura yang hadir dan ikut serta dalam percakapan itu. Kehadiran seseorang lain (O3) dalam adegan percakapan memang sering dapat mempengaruhi bentuk ujaran yang akan dituturkan.

Perubahan kode bahasa yang disebabkan oleh hadirnya $\mathrm{O} 3$ ini dapat terjadi karena alasan bermacam-macam, antara lain karena ingin melibatkan O3 dalam percakapan, ingin merahasiakan sesuatu, agar $\mathrm{O} 1$ yang ingin memberikan kesan kepada $\mathrm{O} 3$ bahwa O2, sebetulnya ialah orang terhormat, agar tidak mengganggu $\mathrm{O} 3$, dan untuk menghormati O3. Kemunculan O3 dalam stiker humor kadang tidak terlalu tampak jelas. Jadi, O2 hanya menduga-duga bahwa stiker humor itu terkait dengan orang tertentu atau O3.

Di kalangan masyarakat Jawa banyak anak yang memakai tingkat tutur ngoko untuk berbicara kepada orangtua mereka. Akan tetapi, jikalau ada tamu penting banyak juga gadis-gadis yang lalu menggunakan krama untuk berbicara kepada orangtua mereka. Maksudnya ialah agar tamu itu mempunyai kesan bahwa ia adalah gadis yang tahu adat sopan santun, dan bahwa orangtuanya ialah terbilang orangtua yang terhormat.

Dalam hal ini, bentuk linguistik yang diubah dapat berwujud bahasanya secara keseluruhan, dapat tingkat tuturnya saja, dapat hanya terbatas pada pilihan katakatanya yang dianggap penting, dapat juga terbatas pada unsur-unsur suprasegmentalnya saja. Contoh-contoh perubahan bahasa, tingkat tutur, dan pilihan kosakata di atas yang terkait dengan kehadiran O3 tampak dalam stiker humor di bawan ini.

(8) Yg mau lebaran Sabtu silakan.. Yg mau lebaran Minggu ya monggo... 
Yg penting jangan sampe kambingnya walk out...

(9) Pengumuman Pengumuman!

Bagi Anda yang Merasa sesuai Persyaratan ini

Sehat

Cukup Umur

Gemuk

Ditunggu Panitia Kurban Besok!!

Selamat Idul Adha

(10) PSIKOLOGI PEMBENCI JOKOWI

Jokowi itu

banyak yang tidak sa-

dar bahwa sejak Pil-

pres yg lalu, otak me-

reka sudah dicuci de-

ngan kampanye hitam

\& fitnah. Akibatnya, usai Pilpres

Otak mereka masih saja kotor de-

ngan kebencian \& niat untuk meng-

hujat Jokowi...

(12) Jangan menolak laki-laki

karena kurang mapan,

sebab kalo udah mapan

seleranya bukan kamu

(13) tante tante

kayak $A B G$

$A B G$

Kayak tante tante

Pada contoh di atas tampak perubahan bentuk bahasa yang mempertimbangkan kehadiran O3. Hal tersebut tampak dalam kosakata Yg mau lebaran Sabtu silakan, Yg mau lebaran Minggu ya monggo, Anda, PSIKOLOGI PEMBENCI JOKOWI, laki-laki, dan tantetante. Kesemua itu menggambarkan pengaruh kehadiran O3.

\section{Kehendak Penutur}

Orang pertama dalam bertutur tentu memiliki maksud tertentu. Maksud O1 ini mempengaruhi bentuk bahasa yang digunakan. Pada suatu saat karena maksud tertentu seseorang mungkin menggunakan krama biar tampak lebih sopan tetapi bisa saja disaat yang lain mengubahnya dengan ngoko terhadap $\mathrm{O} 1$ yang sama. Jikalau tidak ada maksud-maksud tertentu yang terkandung di hatinya, O1 berbicara dengan bahasa Jawa madya tingkat hormat. Akan tetapi, manakala ia ingin meminta sesuatu, terutama permintaan yang agak serius, maka $\mathrm{O} 1$ berpindah menggunakan krama yang paling hormat.

Maksud dan tujuan pembuat stiker adalah sebagai curahan hati dan menciptakan rasa humor tanpa menyinggung orang lain. Konteks ini merupakan Ends yang berkaitan dengan maksud dan tujuan yang ingin dicapai dalam pembicaraan. Rupa-rupanya, perubahan maksud hati 01 dapat mempengaruhi bentuk ujarannya. Berikut ditampilkan contoh yang mengggambarkan maksud penutur yang bisa mempengaruhi bentuk bahasa yang digunakan.

(14) WARNING ...!! COWOK Pake MATIC.!

SEKALIAN AJA.. BIBIRNYA Pake LIPSTIC.!

(15) Inyong asli wong CILACAP

Ora percaya Gari

Ditakoni Bae mesti semaure karo

Basa NGAPAK

UJAR UJARE SING NGOMONGE KARO

BASA NGAPAK WONG CILACAP TOK $M B O K \ldots$

(16) IBU ... Tanpa do'a mu Aku tidak mungkin bisa seperti ini Terimakasih IBU ...

(17) CANTIK ITU RELATIF. TAPI....

CAMERA 360 ITU ALTERNATIF

Wacana di atas pada dasarnya berisi kalimat-kalimat yang menonjolkan maksud penutur. Pada contoh (14) O1 ingin mengedepankan maksudnya bahwa lakilaki itu yang keliatan gagah kalau tidak memakai kendaraan metik. Selanjutnya data (15) O1 ingin menunjukkan asal daerahnya yaitu Cilacap dengan segala kelebihan yang dimiliki daerahnya. Data nomer (16) bermaksud memberikan penghormatan pada seorang ibu. Sedangkan contoh nomer (17) bermaksud menunjukkan bahwa banyak orang sekarang terkesan cantik hanya di kamera 
hanya di media sosial saja, tidak tampak cantik yang sesungguhnya.

\section{Warna Emosi Penutur}

Konteks yang terkait dengan pembuat stiker juga menyangkut warna emosi yang dimiliki pembuat stiker. Tidak hanya warna emosi tetapi menyangkut Key berkenaan nada suara, cara, dan emosi, seperti: santai, serius, senang, sedih, dan sebagainya. Bagaimana nada dan suasana di sekitar pembuat stiker. Suasana sekitar terkait dengan stiker yang akan dihasilkan. Hal ini juga akan mempengaruhi adegan dan norma kebahasaan yang dipakai pembuat stiker. Contoh konteks yang terkait dengan warna emosi kreator stiker humor tampak pada contoh di bawah ini.

(18) seorang ibu sanggup

memelihara 10 anak

tetapi

10 anak belum tentu

dapat memelihara

satu orang ibu

(19) $A K U$

$W E S$

BOSEN

CALM

TERUS

(20) DANGER

PEMILIK MOTOR INI

MUDAH TERBAKAR

EMOSINYA

(21) DIPAKE

NGESELIN

DIJUAL

DIOMELIN

(22) Boleh saja Jomblo Berkata

"Aku Tegar, Aku Kuat”

Tapi Tetep Ajah dlm hati

Ngenes...

SaBarr Yahh..

Berkaitan erat dengan faktor kehendak dan maksud O1 ialah warna emosi yang O1 alami pada waktu ia hendak bertutur. Warna emosi O1 ini sangat mempengaruhi bentuk tuturnya. Seorang penutur yang gugup melontarkan ujaran-ujaran yang kurang teratur, banyak frasa-frasa yang putus, banyak pengulangan yang tak perlu, banyak inversi-inversi yang membingungkan pengertian. Demikian juga penutur yang emosional terlontar penggunaaan kosakata yang emosional, umpatan-umpatan, dan sumpah serapah.

\section{Nada Suasana Bicara}

Berhubungan erat dengan warna perasaan $\mathrm{O} 1$, maka nada suasana bicara yang secara keseluruhan dapat mempengaruhi persaan $\mathrm{O} 1$ juga lalu berpengaruh pada macam dan bentuk tutur yang akan dilontarkan seorang $\mathrm{O} 1$. Suasana pesta, suasana pertemuan yang menggembirakan seperti pesta pada perkawinan sudah tentu nadanya serba indah. Biasanya diisi dengan pidato dan sambutan yang beragam indah pula. Konteks ini dapat dikatakan sama setting dan scene berkenaan waktu, tempat, dan suasana pembicaraan.

Sebaliknya pidato-pidato atau sambutan dalam upacara penerimaan jenasah dan pemakaman jenazah biasanya disampaikan dengan corak bahasa yang mengandung kesedihan, keseriusan, dan kekeramatan. Corak bahasa yang demikian itu sesuai dengan corak rasa kesedihan dan kekeramatan yang menyelubungi upacara penerimaan jenasah dan pemakaman itu.

Pada garis besarnya, nada bicara dan citarasa bicara ini mempengaruhi bentuk ragam tutur yang akan dilontarkan oleh O1. Dalam hal ini bentuk ragam stiker humor biasanya muncul dan dipengaruhi oleh nada bicara dan citarasa bicara O1. Bentuk stiker humor yang dihasilkan meliputi tiga ragam bahasa: ragam bahasa santai, ragam bahasa formal, dan ragam bahasa indah. Suasana bicara yang santai, yang tidak mementingkan adanya formalitas, biasanya diisi orang dengan ragam bahasa yang santai pula, kecuali apabila hadir disitu $\mathrm{O} 2$ atau $\mathrm{O} 3$ yang dianggap amat terhormat oleh O1. Suasana bicara yang formal atau yang dinas, seperti suasana perkuliahan dalam kelas, suasana 
di dalam rapat dinas, dalam sidang praperadilan, biasanya juga diisi dengan pembicaraan-pembicaraan yang dibawakan dengan ragam bahasa formal. Selanjutnya suasana bicara yang dianggap indah-indah, yang seremonial, seperti terdapat di dalam pesta perkawinan tradisional, sebagian dari upacara keagamaan di masjid, suasana di pembacaan puisi, biasa diisi dengan ragam bahasa indah, yang mengandung ungkapan-ungkapan literer. Berikut contoh contoh yang menggambarkan nada suasana bicara.

(23) esia pa si lo..??

Pake baju ukuran XL, sok akrab panggil" gw fren, lo piker lo hebat kaya MENTARI, pake acungin jempol sgala!!

Lo kira

gw bakal simPATI gtu sama lo??

Liat muke lo ga Ceria,

dan ga smart

lebay bgt $n$

Jangan sok AXIS deh loh.

(24) Untuk yg JOMBLO

tolong jangan

berdo'a minta

hujan...

kasian sodara2

kita di JAKARTA

(25) WAKTUNYA

PDKT KE

DOSEN PEMBIMBING SKRIPSI

(26) SKRIPSI

Penulisannya sistematis

Penggunaan Bahasa Indonesia

yang baku dan sesuai EYD

Berisi penelitian kasus pada

bidang ilmu tertentu

Dikejar dosen pembimbing

SULIT,

NGEBLOG

Penulisannya ga sistematis, dibebaskan sesuai keinginan penulis

Penggunaan bahasanya bebas

boleh dicampur pake bahasa

daerah dan bahasa gaul

Isinya bisa berupa informasi

curhatan, dagangan, dll, pokoknya

disesuaikan dengan diri kita lah

Dikejar fans yang nunggu

Postingan kita

MUDAH
Pada data di atas tampak pelbagai data dengan pelbagai nada dan suasana yang berbeda. Dari pelbagai bentuk stiker itu jelas terungkap dan dapat dibedakan adanya suasana tergesa-gesa, suasana yang memerlukan kejelasan dan ketelitian, dan suasana yang menghendaki keseriusan. Dalam suasana yang penuh dengan rasa tergesa-gesa, biasa digunakan orang ragam tutur yang amat ringkas. Demikian pula apabila dirasa bahwa suasana itu diliputi oleh rasa keakraban, maka ragam tutur yangdiringkaslah yang biasanya dipakai. Dalam ragam ini terdapat banyak penanggalan dan kelonggaran-kelonggaran kaidah bahasa. Dalam suasana yang menuntut adanya ketelitian dan kejelasan, maka ragam bahasa lengkaplah yang biasanya dipakai. Dalam ragam lengkap segala sesuatu harus disampaikan dengan setuntas-tuntasnya, tidak multi tafsir. Yang diutarakan semua yang hadir harus jelas.

\section{Pokok Pembicaraan}

Konteks yang lain lagi, berupa topik atau pokok pembicaraan dan urutan bicara. Dengan topik tertentu, suatu interaksi dan komunikasi dapat berjalan dengan lancar. Namun, dalam kehidupan keseharian, apa yang disebut topik sering sangat kompleks sehingga para ahli wacana menamakannya kerangka topik. Pada suatu kelas kuliah misalnya Perencanaan Kota, ada kelompok yang berbicara tentang pembangunan daerah misalnya, orang berbicara tentang pembangunan jalan, gedung, masalah kemacetan, masalah banjir, pembangunan di bidang mental spiritual. Tetapi, ada pula kelompok yang berbicara politik, atau topik yang lain). Topik dalam stiker meliputi pelbagai hal. Pokok pembicaraan dapat meliputi sosial, politik, hukum, agama, pendidikan, dan budaya. Urutan bicara tidak dibicarakan secara mendalam mengingat wacana stiker merupakan wacana tulis. Contoh konteks yang terkait dengan topik dalam stiker humor tampak pada contoh di bawah ini. 
(27) Lah piye to?

Wong niat PDKT

kok malah dipanggil OM

Lek ngene kiy

opo yo ra

NGENES !!!

(28) Sorry...

Orangnya

Lagi

FiTnES

AWAK'E FIT

ATINE NGENES

(29) “MASALAH dating

bukan untuk

membuat GALAU.

Tapi melatih

untuk lebih

(30) Atine wong lia sapa

sing ngerti. Apamaning

nek ora gelem takon.

Mikir nganti buthak

Ya ora bakal ngerti

(31) NIKAH

KACAU

gak nikah

GALAU

(32) "Nikmatilah GALAU

selagi bisa.. karena

jika sudah menemukan

orang yg tepat

untuk DICINTAI.

Mungkin gak

bisa merasakan

GALAU lagi."

Ada kaitanya dengan suasana bicara ialah bab apa yang dipercakapkan. Pokok percakapan seringkali mempengaruhi warna suasana bicara yag harus mewadahinya. Pada waktu membicarakan suatu masalah, seperti banjir atau kemacetan, walaupun O1 dan O2 samasama dari Jawa, dari Sunda, dari Madura, biasanya bahasa Indonesialah yang dipakai. Pokok pembicaraannya semua harus pada masalah banjir dan kemacetan. Kalau orang -orang mempercakapkan masalah yang lain tentunya hal demikian tidak tepat.

\section{Urutan Bicara}

Sedangkan contoh konteks yang terkait dengan urutan pembicaraan dalam stiker humor tampak pada contoh di bawah ini.

\author{
(33) SKRIPSI OH SKRIPSI \\ BAB 1 KELAR \\ BAB 2 LANCAR TANPA HAMBATAN \\ BAB 3 PENELITIAN SUKSES \\ $B A B 4$ SUKSES BANGET \\ JUDUL JUGA BELUM ACC \\ NGIMPI YA TONG, BANGUN TONG \\ (34) JOKOWI SAH JADI PRESIDEN \\ AHOK SAH JADI GUBERNUR \\ AKU SAH JADI PACAR KAMU \\ (35) PAGI, HUJAN ABU... \\ SIANG, HUJAN AIR.. \\ MALEM NYA? "DIHUJANI \\ KENANGAN”
}

Di dalam satu kerangka topik masing-masing menyampaikan sesuatu yang menjadi perhatiannya. Menurut Grice mereka masing-masing menyampaikan kontribusinya yang masih relevan dengan kerangka topik di dalam interaksi yang bersangkutan. Selaras dengan maksim yang ada, setiap peserta tutur harus memberi kontribusi sesuai yang diperlukan mitra tutur kecuali memiliki tujuan lain misalnya untuk menggapai humor.

Peserta ujaran di dalam suatu interaksi dengan kerangka topik atau tidak, selama proses interaksi tersebut berorganisasi tentang topik yang mereka ajukan. Mungkin mereka berakhir dengan suatu topik yang menarik untuk dibicarakan bersama atau berhenti pada garis besar yang masih terangkum di dalam kerangka topik.

Dalam suatu percakapan yang melibatkan adanya tanya jawab, ujaran dan tanggapan, saran dan sambutan, perintah dan penolakan, seru dan sahut, terdapatlah paling tidak dua orang yang aktif ikut mengambil bagian percakapan. Ada paling tidak dua orang O1. O1 pertama sebagai pengambil inisiatif bicara agak lebih bebas dalam menentukan bentuk tutur yang akan dipilih. Penilaian bentuk tutur akan dibuat 
berdasarkan pada hasil penilaiannya akan faktor-faktor penentu tutur yang kebetulan ada pada waktu itu misalnya keadaan $\mathrm{O} 2$, hadirnya O3, dan nada suasana bicara. Orang kedua yang harus menjawab atau menyahut atau menanggapi 01 pertama, tidaklah sebebas $\mathrm{O} 1$ pertama dalam memilih bentuk tuturnya.

\section{Bentuk Wacana}

Konteks bentuk wacana atau Act sequence berkenaan dengan bentuk dan isi tuturan. Konteks yang terdapat dalam interaksi dan komunikasi yakni berupa pesan beserta isinya. Seseorang yang pandai bergurau, misalnya dapat menyampaikan berupa suatu berita penting sehingga benar-benar diterima sebagai berita sambil berhumor. Pesan dan isi dibungkus dengan humor, yang dalam bahasa Jawa dikenal dengan guyon parikena. Di Jawa Timur terdapat kebiasaan di kalangan sementara orang yang pandai menyampaikan isi hati mereka lewat parikan. Stiker humor banyak juga yang disampaikan melalui parikan ini. Contoh konteks yang terkait dengan pesan atau isi dalam stiker humor tampak pada contoh di bawah ini.

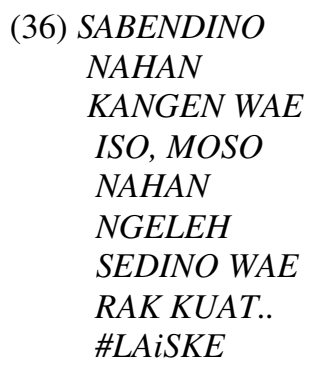

\section{WWW.TWITTER.COM/GAMBARKOCAK}

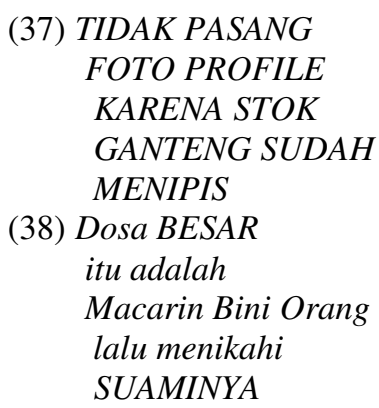

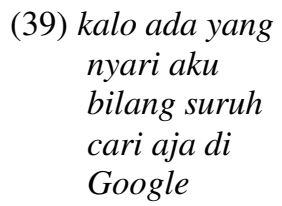
(40) JANGAN LEDEK ORANG GEMUK, KARENA SESUNGGUHNYA ORANG GEMUK ITU PENYAYANG. MELIHAT MAKANAN SELALU BERUCAP. "SAYANG BANGET NIH KLO GAK DIHABISIN."

Dari konteks yang terkait dengan isi atau pesan dapat ditampilkan contoh berikut.
(41) Jangan biarkan
Setan tertawa
Karena kita:
Subuh kesiangan.
Duhur kerepotan.
Ashar diperjalanan..
Magrib kecapean.
Isya ketiduran..
(42) fotonya
baru diCUCI
skarang
lagi diJEMUR
besok deh
diPAKE
(43) $J O M B L O=S E N D I R I$
SENDIRI = MANDIRI
$M A N D I R I=B A N K$
$B A N K=B A N Y A K D U I T$
jomblo itu banyak duit
bisa aja lu tong

(44) ADA YANG LAGI RIBET CARI ILMU, ADA YANG LAGI RIBET CARI REZEKI, TAPI YANG PALING RIBET PASTI YANG LAGI CARI MUKA TUH...

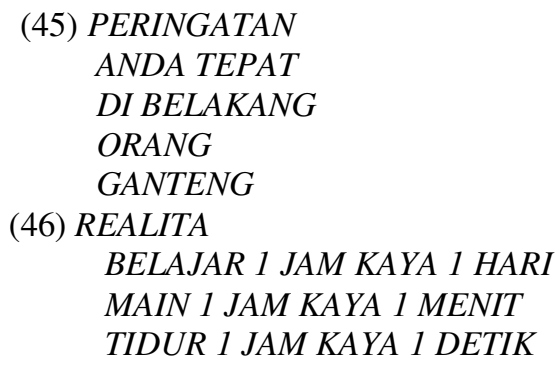

(45) PERINGATAN ANDA TEPAT DI BELAKANG ORANG GANTENG

(46) REALITA BELAJAR 1 JAM KAYA 1 HARI MAIN 1 JAM KAYA 1 MENIT TIDUR 1 JAM KAYA 1 DETIK 
Pada contoh di atas tampak pelbagai bentuk wacana yang dipengaruhi pelbagai konteks tuturan lain. Selain itu, banyak muncul bentuk stiker humor yang bernada sarkastik. Di dalam perkembangan pemikiran selanjutnya, Hymes juga memasukan genre, suatu kategori komunikasi yang dapat berupa puisi, umpatan, doa, lelucon, ungkapan, iklan, pelbagai surat dan lain-lain yang huruf pertamanya ' $G$ ' merupakan huruf terakhir dari akronimnya yang terkenal, SPEAKING, Contoh dari semua konteks dalam stiker yang dipakai sebagai komunikasi adalah.

(47) Godhong waru cak tibane mlumah Kegowo angin mlebu omah: Omonge cak jare Ngibadah Gak ngerti jebule njarah

(48) Tuku lenga rek jok lali terasi terasi ngono gawe nyedepi:

Elinga rek jamane Reformasi Sing korupsi mesthi Billahi

Dari kedua contoh di atas terlihat pelbagai konteks yang ada di ataranya berupa pesan berserta isinya yang disampaikan melalui parikan. Data di atas terdapat beberapa kesalahan penulisan dari pembuat stiker. Di antara kesalahan yang ada yakni kegowo yang baku kegawa 'terbawa'

Di dalam suatu masyarakat, biasanya terdapatlah beberapa macam wacana yang bentuknya sudah mapan. Wacana-wacana seperti surat-menyurat dinas, perundangundangan, percakapan dengan telepon, telegram, pidato pembukaan atau penutup suatu lokakarya, seminar, konferensi, atau pidato seremonial lainnya.

\section{Sarana Tutur}

Konteks ini berkenaan dengan instrumentalities yaitu menunjuk pada saluran dan bentuk bahasa yang digunakan, saluran menyangkut: lisan, tulis, telepon, semapore, dan sebagainya, sedangkan bentuk bahasa menyangkut: ragam, dialek, variasi, register, dan sebagainya. Konteks berikutnya yang ada dalam penelitian ini tentunya berupa tulis yaitu stiker humor.

Kebiasaan orang Indonesia dalam komunikasi ialah mereka lebih berhati-hati apabila mereka menyampaikan berita secara tertulis. Hal ini sangat berbeda di dalam saluran komunikasi tulis berupa stiker. Peserta tutur begitu bebasnya membuat stiker tanpa mengindahkan norma berkomunikasi antarsesama. Contoh konteks yang berwujud saluran komunikasi dalam stiker humor tampak pada contoh di bawah ini.

(49) kalo lo udah mati-matian ngejar cewek tapi gak dapet juga positif thingking aja..... mungkin jodoh lo cowok....

\section{(50) KARENA PADA AKHIRNYA \\ COWO SIX PACK \\ BAKAL KALAH SAMA COWO YANG NGASIH IPHONE SIX}

\section{(51) SANTAI MBLO...!! BESOK KALO UDAH DEKET KIAMAT \\ JUMLAH CEWEK \\ 5:1 DIBANDINGKAN COWOK}

(52) Syukurilah! Jangan sesali Kekurangan pasangan anda. Jika dia sempurna, Tentu dia tak bersedia Menikah dengan anda.

(53) SABAR itu ILMU TINGKAT TINGGI

Belajarnya setiap hari,

Latihannya setiap saat, Ujiannya sering mendadak, Sekolahnya seumur hidup.

(54) "BUAT AKU,

SEMUA HARI

ITU SELASA.

SELASA ADA

DI SULGA

KALO BALENG

KAMU."

Berkaitan dengan bentuk wacana, sarana tutur juga mempengaruhi bentuk ujaran. Yang dimaksud dengan sarana tutur 
ialah sarana yang dipakai menyampaikan tutur itu. Pertama-tama dapat kita sebut adanya bahasa lisan dan bahasa tulis. Sudah pasti sarana tutur dalam penelitian ini dengan bahasa tulis semua.

Pada kebanyakan masyarakat, bahasa tulis biasanya terikat pada ragam bahasa atau bahkan pada bahasa tertentu. Bahasa tulis terikat oleh pelbagai aturan. Dalam stiker humor segala aturan sengaja dilanggar dengan tujuan tertentu yaitu untuk berhumor.

\section{Adegan Tutur}

Adegan tutur juga mempengaruhi bentuk-bentuk ujaran. Yang termasuk dalam istilah adegan terutama ialah faktorfaktor tempat, waktu, dan peristiwa tutur. Tempat dimana percakapan sedang berlangsung sering sangat memepengaruhi pemilihan cara berbahasa dalam stiker humor. Demikian juga waktu percakapan atau stiker itu dibuat sangat mempengaruhi bentuk stiker.

(55) PACARAN JAMAN DULU SEPIRING BERDUA

PACARAN JAMAN SEKARANG SPINGBED BERDUA

(56) Anak saya donk jeng, sekolahnya

Di Amerika.

Wow, berangkat dari

Rumahnya jam berapa?

(57) Jaman sekarang Nanya 'kamu di mana' Itu maksudnya biar gak papas an di jalan

(58) Anakku... KULIAHLAH ENGKAU SAMPAI S3 JANGAN MAU KALAH SAMA SAMSUNG ... DIA UDAH S5....

Pada data di atas tampak betapa tempat sangat mempengaruhi bentuk stiker humor yang dihasilkan. Demikian juga waktu juga menentukan stiker humor yang dihasilkan.

\section{Lingkungan Tutur}

Konteks lain berhubungan dengan lingkungan. Lingkungan tutur dapat menyangkut tempat sekelompok orang dan waktu yang menyangkut suatu acara. Lingkungan ini menyangkut suatu yang terjadi pada saat itu. Lingkungan sedang membicarakan konflik KPK dan Polisi, stiker humor yang muncul pasti dipengaruhi lingkungan yang sedang membicarakan konflik itu. Namun, bentuknya tentu dikemas dalam humor.

Pada suatu pagi, dalam suatu kelas para mahasiswa sedang berdiskusi dipimpin oleh seorang dosen tentu akan berbeda tuturanya dengan tuturan di warung di malam hari. Demikian juga bentuk stiker humor yang dihasilkan akan berbeda manakala dihasilkan oleh lingkungan yang berbeda. Contoh konteks yang terkait dengan tempat dalam stiker humor tampak pada contoh di bawah ini.

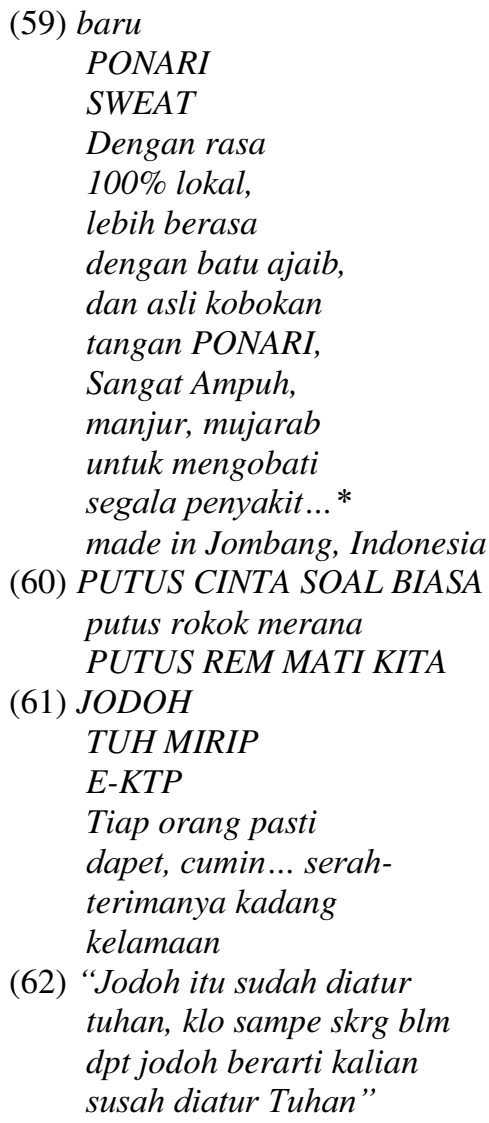


Pada contoh di atas tampak jelas bahwa lingkungan sangat mempengaruhi stiker humor yang muncul. Sesuatu yang terjadi di lingkungan sangat mempengaruhi stiker humor. Apa yang terjadi di luar selalu memberi inspirasi terhadap stiker humor yang akan terbentuk.

\section{Norma Kebahasaan}

Konteks terakhir berupa norms of interaction dan norms of interpretation yaitu menyangkut norma-norma atau kaidah-kaidah dalam berbahasa, dan penafsiran terhadap tuturan dari lawan bicara. Konteks ini dapat berupa kode. Seseorang yang mengungkapkan isi hatinya dalam bahasa daerah kepada temannya akan merasa lebih bebas, akrab, lebih komunikatif, dan mudah berkembang ke arah hubungan pribadi.

Ada suatu gejala yang berkembang di masyarakat biar keliatan akrab dan tidak berjarak maka digunakan kode bahasa daerah yang tidak baku. Baik meliputi tataran fonologis, morfologis, sintaktis, maupun semantis. Contoh konteks yang terkait dengan kode dalam stiker humor tampak pada contoh di bawah ini.

Pada suatu masyarakat bahasa sering terdapat norma-norma kebahasaan yang khusus. Aturan-aturan kebahasaan ini kahirnya juga dapat mempenagruhi laternatif-alternatif pilihan bentuk ujaran yang akan dituturkan oleh O1. Contoh konteks yang terkait dengan norma kebahasaan dalam stiker humor tampak pada contoh di bawah ini.

\footnotetext{
(63) 2 Anak Cukup, 2 Bini,

Aku

Pikir2 Dulu

(64) cuma cowok

"KERE"

yang

mengatakan

cewek itu

"MATRE”
}

\author{
(65) Aku setia \\ Karena kamu \\ Setia \\ (66) NGEBUT ITU \\ IBADAH!!!! \\ SEMAKIN NGEBUT \\ SEMAKIN DEKAT \\ DENGAN TUHAN \\ (67) PUNYA MOTOR BEBEK \\ TAPI KOK KETEMU \\ BANJIR TAKUT \\ BEBEK KAN BISA BERENANG \\ PUNYA MOTOR LAKI \\ TAPI KESENGGOL \\ NANGIS \\ MOTOR BANCI DONK???
}

(68) Duh gusti kula nyuwun kiat mlarat

(69) Bapak polah

Ibu obah

Anak tambah

Pada contoh di atas tampak pelbagai stiker humor dengan pelbagai variasi bahasa yang dipakai. Pelbagai variasi itu menyangkut ragam dan tingkat tutur. Pelbagai stiker itu menggunakan ragam santai dan tidak baku. Pelbagai stiker itu juga menggunakan tingkat tutur ngoko dan krama.

\section{SIMPULAN}

Aspek sosiolinguistik terdiri atas dua aspek yakni aspek sosial kemasyarakatan dan aspek kebahasaan. Hymes (1972) merumuskan pendapatnya tentang aspek sosiolinguitik dengan menyebutnya sebagai konteks dengan singkatan SPEAKING. Fishman (1968) dengan sebuah konsep yang disimpulkan dalam pernyataan: "Who speak, What language to whom, when and what end" siapa berbicara dengan bahasa apa, kepada siapa, kapan dan mengenai masalah apa. Pendapat yang lebih luas dikemukakan oleh Poedjosoedarmo. Konteks tuturan diartikan dengan komponen tutur yang meliputi 12 hal yang disingkat dengan memoteknik O, O, E, M, A, U, B, I, C, A, 
R, A. Adapun Leech menyebut konteks dengan aspek-aspek situasi tutur meliputi 5 (lima) hal yang merupakan kriteria di dalam studi variasi bahasa yakni (1) Penutur dan lawan tutur; (2) Konteks tuturan; (3) Maksud tuturan; (4) Tuturan sebagai bentuk tindakan atau aktivitas; dan (5) Tuturan sebagai produk tindak verbal.

\section{DAFTAR RUJUKAN}

Allan, Keith, 1986, Linguistic Meaning, Jilid I, London: Routledge \& Kegan Paul.

Andersen, E. (2014). Speaking With Style (RLE Linguistics C: Applied Linguistics): The Sociolinguistics Skills of Children. Routledge.

Fishman, J.A., 1968, Readings in the Sociology of Language, The Hague: Mouton.
Hymes, Dell, 1972, Models of Interaction of Language and Social Life, di Gumperz, John J. and Hymes, Dell (Eds), Directions in Sociolinguistics, New York: Holt, Rinehart and Winston, Inc.

Raskin, Victor, 1984, Semantic Mechanism of Humor, Cambridge: Cambridge University Press.

Roberson, D. (2016). Yada Yada Yada: A Sociolinguistic and Rhetorical Analysis of Humor in Seinfeld. 2016 NCUR.

\section{UCAPAN TERIMA KASIH}

Dengan dimuatnya artikel ini, penulis menghaturkan terima kasih dan penghargaan yang setinggi-tingginya kepada penyunting Jurnal Lokabasa. 